\title{
LA COSA JUZGADA FRAUDULENTA EN LA JURISPRUDENCIA DE LA CORTE INTERAMERICANA DE DERECHOS HUMANOS: IMPLICACIONES PARA EL ESTADO DE DERECHO CONTEMPORÁNEO*
}

\author{
Fecha de recibido: 2 de octubre de 2014 \\ Fecha de aprobado: 1 de diciembre de 2014 \\ Artículo de reflexión
}

\section{Alfonso Chacón Mata*}

Forma de citación: Chacón, A. (2015). La cosa juzgada fraudulenta en la jurisprudencia de la Corte Interamericana de Derechos Humanos: implicaciones para el Estado de derecho contemporáneo. Revista Prolegómenos. Derechos y Valores, 18, 35, 169-188.

\section{Resumen}

El presente artículo recoge de forma sistémica algunos pronunciamientos de la Corte Interamericana de Derechos Humanos sobre los juzgamientos que se realizan en los ordenamientos jurídicos internos, en los que no se respetan las garantías del debido proceso reconocido e instaurado en la Convención Americana sobre Derechos Humanos en su artículo octavo. La descripción de la teoría denominada "cosa juzgada fraudulenta" será el objeto de este artículo. El cual busca determinar qué es la cosa juzgada fraudulenta o aparente y sus elementos. Ya que es improcedente establecer procesos anómalos a las mínimas garantías propias de defensa y demás variables inherentes al debido proceso como son la verdad real y objetiva de los hechos a justiciar. Práctica malsana que genera impunidad hacia el sujeto procesado y un marco improcedente que lesiona el debido proceso de las víctimas, como emblema de la justicia procesal.

\section{Palabras clave:}

Debido proceso, cosa juzgada fraudulenta, independencia del juez, imparcialidad, principio de non bis in idem, Estado contemporáneo.

* Artículo resultado del trabajo de investigación realizado en el marco del proyecto de investigación inscrito en el Instituto de Investigaciones Jurídicas de la Facultad de Derecho de la Universidad de Costa Rica: "Lineamientos jurisprudenciales de la Corte Interamericana de Derechos Humanos y sus alcances para el Estado de derecho" (2013-2014).

** Abogado. Profesor de la Licenciatura de la Facultad de Derecho de la Universidad de Costa Rica y de la maestría en Derechos Humanos del Instituto de Estudios Latinoamericanos de la Universidad Nacional de Costa Rica. Licenciado en Derecho por la Universidad de Costa Rica; máster en Derecho del Trabajo y Seguridad Social por la Universidad Estatal a Distancia y máster en Protección Internacional de Derechos Humanos, Universidad de Alcalá (España). Correo electrónico: achaconm@yahoo.com 


\title{
THE THING JUDGED FRAUD AT THE JURISPRUDENCE OF THE INTERAMERICAN COURT FOR HUMAN RIGHTS. IMPLICATIONS FOR THE STATE OF CONTEMPORARY RIGHT
}

\begin{abstract}
Summary
The present article collects in a systematic form some pronouncements from the Interamerican Court for Human Rights about the trials that are been done at the internal legal orderings, in which the guarantees of the acknowledged proper process are not respected and established at the American Convention about Human Rights in its Eighth (8th) article. The description of the theory denominated "Thing Judged Fraud" will be the object for this article. Which tries to determine what is the Thing Judged Fraud or apparent and its elements. As it is improper to establish an abnormal process to the minimum proper defense guarantees and other variables inherent to the proper process as it is the real objective truth of facts to be judged. Unhealthy practice which generates impunity toward the subject being processed and an improper frame that wounds the proper process of victims, as emblem of Procedural Justice.
\end{abstract}

\section{Keywords:}

Proper process, thing judged fraud, judge independence, impartiality, principle of non bis in idem, Contemporary state.

\section{A COISA JULGADA FRAUDULENTA NA JURISPRUDÊNCIA DA CORTE INTERAMERICANA DE DIREITOS HUMANOS: IMPLICAÇÕES PARA O ESTADO DO DIREITO CONTEMPORÁNEO}

\begin{abstract}
Resumo
O presente artigo recolhe de forma sistémica alguns pronunciamentos da Corte Interamericana de Direitos Humanos sobre os julgamentos que são realizados nos ordenamentos jurídicos internos, nos que não são respeitadas as garantias do devido processo reconhecido e instaurado na Convenção Americana sobre Direitos Humanos no seu artigo oitavo. A descrição da teoria denominada "coisa julgada fraudulenta" será o objeto deste artigo. O qual busca determinar o que é a coisa julgada fraudulenta ou aparente e os seus elementos. Já que é improcedente estabelecer processos anómalos ás mínimas garantias próprias de defensa e demais variáveis inerentes ao devido processo como são a verdade real e objetiva dos fatos a justiçar. Prática malsã que gera impunidade para o sujeito processado e um marco improcedente que lesiona o devido processo das vítimas, como emblema da justiça processual.
\end{abstract}

\section{Palavra-chave:}

Devido processo, coisa julgada fraudulenta, independência do juiz, imparcialidade, princípio de non bis in idem, Estado contemporâneo.

\section{INTRODUCCIÓN}

Se plantea como tema central las implicaciones que tiene para el Estado de derecho actual, la celebración de juicios que menoscaben las prerogativas de imparcialidad judicial o la adecuada motivación de las sentencias - entre otras variables-, siendo que a la postre su inobservancia 
lesiona la credibilidad de las instituciones y somete a grandes injusticias a la persona que espera un dictado de la justicia y se afecta con este mal proceder.

Se hace imperioso dejar por sentado, que el análisis de la cosa juzgada fraudulenta en un foro regional de protección de derechos humanos -como es el caso del sistema interamericano-, cobra relevancia en la medida en que se entienda que la justicia protectora de derechos humanos en el ámbito internacional, cumple un rol de subsidiaridad. El principio de subsidiariedad en el marco del derecho internacional de los derechos humanos (DIDH), supone que son a los Estados, a quienes les corresponde tutelar la vigencia de los derechos humanos en lo interno, y en defecto de la carencia o inobservancia de este acometido, es que la jurisdicción internacional "puede y debe ejercer su competencia" (Del Toro, 2007, p. 24). Correlativamente al hecho anterior, se concibe la protección internacional de los derechos humanos como el efecto inmediato de la jurisdiccionalidad que podríamos denominar como "hacia fuera". Aquí se parte de la idea de que la normalidad del funcionamiento de los ordenamientos jurídicos internos de los Estados, debe orientarse hacia el cumplimiento y protección de los derechos humanos concebidos en el sistema internacional. Y es que esto, así planteado, sería consecuente con el desarrollo histórico de esta materia, que tuvo primero su evolución en los sistemas internos (sobre todo en el área del derecho constitucional) para luego trascender al proceso todavía vigente de internacionalización. Por tanto, ambos sistemas normativos -interno y externo-, se conjuntan de manera armónica, capaz de integrarse en uno solo. Aquí se aplica el carácter de subsidiaridad del DIDH con respecto al derecho interno que regula este asunto. Al respecto, Abregú nos dice

Esta subsidiariedad de la protección internacional nos lleva a la necesaria complementariedad entre las dos aristas del DIDH: la protección internacional de los derechos humanos y su aplicación en el ámbito interno. Así, entendemos que deben explorarse paralelamente estas dos dimensiones de esta rama del derecho. (1998, p. 4).

De acuerdo con lo anterior, el presente artículo tiene trascendencia en tanto que la jurisprudencia de la Corte Interamericana de Derechos Humanos (en adelante Corte IDH) en materia de cosa juzgada fraudulenta, supone que los justiciables de los Estados partes de la Convención Americana sobre Derechos Humanos, pueden valerse de las provisiones que se van a detallar a lo largo de este trabajo. A la luz de la consabida subsidiariedad y plenitud hermética entre el derecho internacional y el derecho interno, la jurisprudencia a destacar se constituye desde nuestra óptica en un excelente parámetro para potenciar la vigencia del debido proceso y de qué modo este puede ser inobservado.

Para lograr este objetivo se estudiarán los pronunciamientos de la Corte IDH y se analizarán las implicaciones que tiene para el ordenamiento jurídico las prácticas inapropiadas; sus alcances y elementos que coadyuvan para que estas se perpetúen. Terminaremos con algunos desafíos que visualizamos para combatir este tipo de fraude, en el marco del mismo Estado de derecho. Conscientes de esta inadecuada dinámica, en el último aparte se proponen algunas pautas o políticas que deben volverse efectivas para mitigar el estado fraudulento en los veredictos judiciales.

\section{A. Definición de cosa juzgada fraudulenta}

Para iniciar, se precisa la expresión "cosa juzgada" a la luz de la doctrina, para luego desarrollar el concepto de fraudulencia. Para Hitters, la cosa juzgada es "la influencia que ejerce cierta providencia sobre las posibles declaraciones posteriores de cualquier otro órgano; y podríamos definirla como la imposibilidad de variar una sentencia una vez que ha quedado firme" (1977, p. 22). Otros autores sostienen que la cosa juzgada tiene naturaleza sustancial en cuanto influye directa $e$ indirectamente sobre la preexistente situación sustancial (Vellami, 2001). 
A criterio de quien escribe estas líneas, parece más acertada la explicación de Calaza (2001), para quien la cosa juzgada es la imposibilidad de alterar-por medio de un recurso judicial, o en un caso, de una nueva demanda- el contenido de una resolución material o procesal, en el curso de un único proceso, así como sustantiva o de fondo, en el marco de procesos firmes e irrevocables. Aunque claro está, doctrinariamente se distingue entre cosa juzgada formal y cosa juzgada material, siendo que en palabras del célebre jurista italiano Carnelutti (1944), la primera hace inimpugnable la sentencia, mientras que la segunda la hace indiscutible (Hitters, 1977) ${ }^{1}$.

En consecuencia y a manera de síntesis, podemos concluir que la cosa juzgada responde a la potestad que ostenta una determinada jurisdicción para decretar el derecho vigente con un resultado definitorio o en estado de firmeza, que no admite ningún otro remedio judicial para alterar el curso de la pretensión otorgada en sentencia. Para los efectos del artículo vamos a referirnos a cosa juzgada en general, entendiéndola básicamente como aquel asunto fallado y por ende fenecido en los tribunales domésticos o internos.

También se destacan las implicaciones de veredictos jurisdiccionales que arrojan una práctica fraudulenta y la forma de revertir esta última en el orden internacional protector de derechos humanos. Precisamente en esta actitud y práctica de "fraudulencia" descansa el énfasis del presente artículo. Vamos a desentrañar qué ha venido entendiendo la Corte IDH -en su jurisdicción contenciosa- con respecto al ejercicio omiso de garantías procesales y de fondo, que generan actos jurisdiccionales de las autoridades de dictar el derecho, produciéndose un fraude a

\footnotetext{
Se ha dicho igualmente como criterio de distinción, lo siguiente: "La cosa juzgada formal es la expresión que define la imposibilidad de alterar por vía de recurso, el contenido de una resolución judicial firme e irrevocable" (Calaza, 2001, p. 40). Y "La cosa juzgada material es la expresión que define la imposibilidad de enjuiciar, por la vía de un nuevo proceso, un asunto que haya sido objeto de una resolución judicial firme e irrevocable" (Calaza, 2001, p. 43).
}

los intereses de las víctimas pero sobre todo, un engaño al Estado de derecho que tiene sendas consecuencias en la ciudadanía. Antes de llegar a este desenlace propositivo, pasamos a reseñar los alcances de la cosa juzgada fraudulenta en el orden de la Corte IDH, con el objeto de destacar tendencias jurisprudenciales de dicho fenómeno.

\section{B. Análisis de la cosa juzgada fraudulenta en la jurisprudencia interamericana}

En el marco de la jurisprudencia regional emitida por la Corte Interamericana el fenómeno en estudio tiene estrecha relación con la garantía del debido proceso. La aplicación del artículo octavo de la Convención Americana sobre Derechos Humanos, es lo suficientemente analizada a través de los anales jurisprudenciales de la Corte Interamericana. Subrayaremos algunos de los antecedentes, a pesar de que somos conscientes de que podemos omitir otros, que igualmente podrían estimarse como de gran valía.

En concordancia con la Convención y con lo que expresa la Corte Interamericana en repetidas ocasiones, los Estados partes están obligados a suministrar recursos judiciales efectivos a las víctimas de violaciones de los derechos humanos (artículo 25), recursos que deben ser sustanciados de conformidad con las reglas del debido proceso legal (artículo 8.1), todo ello dentro de la responsabilidad general, a cargo de los mismos Estados, de garantizar el libre y pleno ejercicio de los derechos reconocidos por la Convención a toda persona que se encuentre en su jurisdicción (artículo 1.1) (Corte IDH, 1988, párr. 91; 2008a, párr. 77; 2008b, párr. 34).

En opinión consultiva la Corte IDH, caracteriza en un primer momento lo que para ella debe entenderse como debido proceso. Ha dicho que son los requisitos que deben observarse en las instancias procesales para que pueda hablarse de verdaderas y propias garantías judiciales (Corte IDH, 1987a, párr. 27), que "sirven para proteger, asegurar o hacer valer la titularidad o el ejercicio de un derecho" (Corte IDH, 1987b, párr. 25), y son "condiciones que deben cumplirse 
para asegurar la adecuada defensa de aquellos cuyos derechos u obligaciones están bajo consideración judicial" (Corte IDH, 1987a, párr. 28; 1997a, párr. 74; 1997b, párr. 62). Por su parte, la Corte Interamericana en la opinión consultiva "Condición jurídica y derechos de los migrantes indocumentados", declara que:

El amplio alcance de la intangibilidad del debido proceso se aplica no solo ratione materiae sino también ratione personae sin discriminación alguna [...] Tal como ya ha señalado este Tribunal, el debido proceso legal se refiere al conjunto de requisitos que deben observarse en las instancias procesales a efectos de que las personas están en condiciones de defender adecuadamente sus derechos ante cualquier [...] acto del Estado que pueda afectarlos. Es decir, cualquier actuación u omisión de los órganos estatales dentro de un proceso, sea administrativo sancionatorio o jurisdiccional, debe respetar el debido proceso legal [...] Así mismo, la Corte ha indicado que el elenco de garantías mínimas del debido proceso legal se aplica en la determinación de derechos y obligaciones de orden "civil, laboral, fiscal, o de cualquier otro carácter". Esto revela que el debido proceso incide sobre todos estos órdenes y no solo sobre el penal [...] (Corte IDH, 2003a, énfasis fuera de texto).

La anterior opinión refuerza dos variables que son determinantes y desarrolladas en otros contenciosos dentro del sistema interamericano ( $p$. ej. casos: Tribunal Constitucional vs. Perú; Ivcher Bronstein vs. Perú y Baena Ricardo y otros vs. Panamá). Nos referimos a la necesidad procesal de observar las garantías satisfactorias de respeto a la justiciabilidad y defensa de los encausados, y correlativamente; a que tales garantías deben ser eficaces en cualquier foro de atribución de cargos o sanciones para los requirentes.

Adentrándonos en el ámbito contencioso, en el caso Genie Lacayo vs. Nicaragua la Corte IDH manifiesta que el artículo 8 de la Convención que se refiere a las garantías judiciales, consagra los lineamientos del llamado "debido proceso legal" o "derecho de defensa procesal",

[...] que consiste en el derecho de toda persona a ser oída con las debidas garantías y dentro de un plazo razonable por un juez o tribunal competente, independiente e imparcial, establecido con anterioridad por la ley, en la sustanciación de cualquier acusación penal formulada en su contra o para la determinación de sus derechos de carácter civil, laboral, fiscal u otro cualquiera (Corte IDH, 1997a, párr. 74).

Así mismo, la Corte IDH dispuso en el caso de la Masacre de La Rochela vs. Colombia, que "[esta] garantía del debido proceso debe analizarse de acuerdo [con el] objeto y fin de la Convención Americana, cual es la eficaz protección de la persona humana" (Corte IDH, 2007, párr. 200). Nótese entonces que se habla de persona humana en sentido amplio, por lo que este análisis interpretativo parte de valorar los derechos individuales y colectivos a la luz de una serie de principios hermenéuticos, tales como la regla interpretatio pro homine, que significa literalmente "la cláusula del individuo más favorecido. En consecuencia, las interpretaciones restrictivas unilaterales por parte de los Estados de las normas de derechos humanos se deberán tener por inaceptables" (Villán, 2002, p. 236). El principio que nos ocupa, aconseja entonces, interpretar la regla concerniente a un derecho humano del modo más favorable para la persona, es decir, para el destinatario de la protección.

Paralelamente, la citada instancia jurisdiccional, enfatiza que el Estado, para garantizar un debido proceso, debe facilitar todos los medios necesarios para proteger a los operadores de justicia, investigadores, testigos y familiares de las víctimas de hostigamientos y amenazas que tengan como finalidad entorpecer el proceso, evitar el esclarecimiento de los hechos y encubrir a los responsables de los mismos (Corte IDH, 1999, párr. 231; 2003b, párr. 199). 
Más recientemente, la jurisprudencia interamericana a través de diferentes contenciosos tramitados a consecuencia de violación del debido proceso, otorgó medidas de restitución e importantes reformas legales. En los casos todos contra Venezuela -Apitz Barbera y otros; Reverón Trujillo; Barreto Leiva y Chocrón Chocrón-, la declarada violación al artículo octavo de la Convención Americana implicó no solo un reconocimiento expreso de incumplimiento y responsabilidad estatal, sino que además, esta garantía es susceptible de aplicar medidas de reparación integral en el seno de la Corte según lo entiende esta instancia regional.

Ahora bien, la jurisprudencia interamericana viene delineando desde el año 2000 en una serie de fallos, los alcances con respecto a lo que debe entenderse como cosa juzgada fraudulenta y que es a la postre, la intención de este artículo. Tenemos que en el caso Carpio Nicolle y otros vs. Guatemala, la Corte Interamericana adujo que la normativa internacional examina a qué se conoce como este tipo de fraude -artículo $20 \mathrm{del}$ Estatuto de Roma de la Corte Penal Internacional (1998); artículo 20 del Estatuto del Tribunal Internacional para Ruanda (1994) y artículo 9 del Estatuto del Tribunal Internacional para la antigua Yugoslavia (1993) - y expresó que esta actividad defectuosa resulta de un juicio en el que no se han respetado las reglas del debido proceso, o cuando los jueces no obraron con independencia e imparcialidad (Corte IDH, 2004, párr. 131).

Sienta este caso un trascendental precedente al decretar que el juicio realizado ante los tribunales nacionales, estuvo contaminado por tales graves vicios. En consecuencia y como producto de esta actividad defectuosa, no podría invocar

2 En otra sentencia reitera que los graves procedimentales, no solo no cumplen los estándares de la Convención Americana sobre Derechos Humanos, sino que además "no hacen tránsito a cosa juzgada decisiones judiciales originadas en tales hechos internacionalmente ilícitos" (Corte IDH, caso Gutiérrez Soler vs. Colombia, sentencia de 12 de septiembre de 2005, serie C-132, párr. 98). el Estado, como eximente de su obligación de investigar y sancionar, las sentencias emanadas en procesos que no cumplieron los estándares de la Convención Americana. Nos dice que la regla básica de interpretación extensiva contenida en el artículo 29 de dicha Convención, disipa toda duda que se tenga al respecto (2004, párr. $132)^{2}$. A manera de comentario, los parámetros estandarizados se encuentran en el artículo 8 relativo a las garantías del debido proceso y en buena medida en el artículo 25 atinente a la protección judicial. Así las cosas, la Convención Americana es clara en indicar qué se entiende y cómo deben observarse tales parámetros, garantizados en actuaciones tales como el rango de ampliación de las libertades y derechos de la Convención Americana en el orden interno, según se desprende del artículo 1.1 del texto. Por otro lado, una de las disposiciones que refuerzan la tesis de aplicación amplia y evolutiva del debido proceso, la constituye sin duda la obligación de adoptar medidas que subyacen en el artículo segundo de la Convención, para todos los Estados partes.

El otro antecedente que vertió la jurisprudencia interamericana en materia de cosa juzgada fraudulenta, lo tenemos en el caso Almonacid Arellano y otros vs. Chile, que tiene el mérito de aplicar en las consideraciones de su sentencia, los alcances establecidos previamente para reconocer cuándo se está en presencia de un acto jurisdiccional viciado de esta práctica. Se pronuncia con respecto a que el principio de non bis in idem, aun cuando constituye garantía de un derecho humano reconocido en el artículo 8.4 de la Convención Americana, no es un derecho absoluto y, por tanto, no resulta aplicable cuando: (i) la actuación del tribunal que conoció el caso y decidió sobreseer o absolver al responsable de una violación a los derechos humanos o al derecho internacional obedeció al propósito de sustraer al acusado de su responsabilidad penal; (ii) el procedimiento no fue instruido independiente o imparcialmente de conformidad con las debidas garantías procesales, o (iii) no hubo la intención real de someter al responsable a la acción de la justicia (Corte IDH, 2006, párr. 153). 
Se logra determinar en este caso, el suministro fraudulento de justicia, al cumplirse dos de los supuestos señalados. Primero, la causa la llevaron tribunales que no guardaban la garantía de competencia, independencia e imparcialidad. Segundo, la aplicación del decreto ley 2.191 consistió en sustraer a los presuntos responsables de la acción de la justicia y dejar el crimen cometido en contra del señor Almonacid Arellano en la impunidad (2006, párr. 155).

Para finalizar, el caso Nadege Dorzema y otros vs. República Dominicana sirve para enfatizar en que el principio de cosa juzgada implica la intangibilidad o legalidad de una sentencia, solo cuando se llega a esta respetándose el debido proceso de acuerdo con la jurisprudencia de este tribunal en la materia. La Corte considera que en este caso, se presenta el fenómeno de cosa juzgada "aparente" cuando del estudio fáctico es evidente que la investigación, el procedimiento y las decisiones judiciales no pretendían realmente esclarecer los hechos sino obtener la absolución de los imputados y también que los funcionarios judiciales carecían de los requisitos de independencia e imparcialidad (Corte IDH, 2012a, párrs. 195 y 196).

En otras palabras, se abre paso a la realidad empírica y palpable que no requiere mayor grado de complejidad, pudiendo detectarse las anomalías en sus inconsistencias y desarraigo al derecho justo. Estamos ni más ni menos ante un juicio de constatación que evidencia una impunidad a priori, que pretende ser disimulada a través de formalismos jurídicos, como simples requisitos que distan totalmente, de visualizar al proceso como un instrumento de justicia e imparcialidad.

A continuación, se abordarán las dimensiones derivadas y expuestas por el mismo tribunal, con relación a la cosa juzgada fraudulenta y los mecanismos fáctico-normativos existentes para contrarrestar esta actuación contraria al orden democrático.

\section{El deber de los Estados de prevenir la falta de garantías judiciales}

Es importante contrastar las garantías inherentes al proceso -aunque en un principio se asociaron al modelo penal- con la celebración o no, de un debido proceso diáfano. Juan Marcos Rivero, nos dice al respecto que

El modelo clásico (garantista o liberal), es más bien un conjunto de ideas o representaciones relativas a límites de la actividad creadora de derecho de los poderes públicos y a las posibilidades de injerencia del orden jurídico en la esfera privada de los sujetos, y cuya característica principal consiste en la lucha a favor de la eliminación de la arbitrariedad (2001, p. 118).

Para el autor el garantismo posee un carácter mediador entre la norma jurídica y su contexto social, constituyéndose en una forma de reflexión del derecho constitucional que solo considera justo o correcto aquel sistema jurídico que asegure el respeto a la autonomía ética del ser humano, que limite la intervención de las instancias oficiales de control de la manera más precisa posible y que permita determinar racionalmente cuáles son los bienes jurídicos que serán dignos de tutela. Para Courtis (2009), la noción de garantía incumbe a aquellos métodos, mecanismos o disposiciones que sirven para proteger la efectividad de un derecho. Se trata de instrumentos para que ese derecho declarado en el papel se convierta en un derecho operable, ejecutable, exigible.

En esta posición garantista, se observan los derechos elementales de las partes involucradas inicialmente en el proceso penal: acusadores o denunciantes e imputados. Haciendo una traslación a las otras materias judiciales, la observancia de las garantías implica un respeto y una aquiescencia a favor del ser humano, por lo que coincidimos con lo dicho por el exjuez de la Corte IDH, Máximo Pacheco, para quien

La persona humana, por ser un todo dueño de sí y de sus actos, no puede ser tratada por el ordenamiento jurídico como un medio, sino como un fin y, por ello, debe reconocérsele la facultad de obrar conforme a las exigencias del último fin y garantizársele, por parte de los demás integrantes del grupo social, el respeto al uso lícito de su actividad. En consecuencia, la verdadera filosofía de los derechos fundamentales de la persona 
humana descansa en la dignidad y el fin trasciende de ella (1999, p. 57).

En la misma jurisprudencia interamericana se afirmó que el derecho a la tutela judicial efectiva exige a los jueces que dirijan el proceso evitando que dilaciones y entorpecimientos indebidos, conduzcan a la impunidad, frustrando así la debida protección judicial de los derechos humanos (Corte IDH, 2003b, párr. 210). Así mismo se ha dicho en el caso del Tribunal Constitucional vs. Perú, lo siguiente:

Como lo ha señalado este Tribunal, la Convención Americana garantiza a toda persona el acceso a la justicia para hacer valer sus derechos, recayendo sobre los Estados partes los deberes de prevenir, investigar, identificar y sancionar a los autores intelectuales $y$ encubridores de violaciones de los derechos humanos. Con base en esta obligación, el Estado tiene el deber de evitar y combatir la impunidad, la cual ha sido definida como "la falta en su conjunto de investigación, persecución, captura, enjuiciamiento y condena de los responsables de las violaciones de los derechos protegidos por la Convención Americana" (Corte IDH, 2001, párr. 123).

El deber de prevenir se entrelaza con la investigación y eventual ejercicio de la función punitiva estatal, más en una democracia que se precie de efectiva; los actos del poder judicial y sancionatorios en general, encaminados hacia la obtención de la justicia deben operarse sin mayor demora, atendiendo a un sentido de urgencia y resarcimiento de los derechos de las víctimas.

\section{La necesaria independencia del juez que tramita el procedimiento}

Como bien lo expone la organización Transparencia Internacional:

En una democracia, los conceptos de independencia y de rendición de cuentas de un poder judicial se refuerzan mutuamente. La independencia de la administración de justicia se refiere a la institución: no se supone que la independencia debe beneficiar a un juez individual, ni al poder judicial como organismo, sino que debe servir para proteger al pueblo (2000, p. 114).

El deber de un juez consiste en interpretar la ley, así como los principios y supuestos fundamentales que están detrás de ella. Aunque un juez debe ser independiente a este respecto, no tiene el derecho de actuar de manera arbitraria.

La rendición de cuentas está más en consonancia con la constitución de mecanismos públicos así como de normativa afín, que supervise el accionar de las dependencias que ostentan jerarquía o competencias hacia terceros, dadas por el ordenamiento jurídico. También debe observarse que los mismos operadores judiciales no caigan en desafueros al momento de la tramitación de pruebas.

En el ámbito de la jurisprudencia comparada tutelar de derechos humanos, el Comité de Derechos Humanos previsto en el Pacto Internacional de Derechos Civiles y Políticos (PIDCP), considera que en general incumbe a los tribunales de los Estados partes en el Pacto la evaluación de los hechos y las pruebas en un caso concreto, salvo que pueda determinarse que la evaluación fue claramente arbitraria o constituyó una denegación de la justicia. En un caso en particular, el Comité observa que la jueza condenó al autor estimando, entre otras cosas, que las declaraciones de la presunta víctima, aunque hechas fuera del tribunal, no constituían simple testimonio de oídas. Además, la jueza no admitió como prueba la declaración jurada de desistimiento de la presunta víctima, pero aceptó su primera declaración, pese a que ambas fueron igualmente confirmadas por testigos que no conocían en persona los hechos. Por último, el autor tuvo que hacer frente a pruebas dudosas y aún a pruebas que no se presentaron en el tribunal (la apariencia juvenil del testigo de 21 años y la minoría de edad de la presunta víctima). En esas circunstancias, el Comité repara en que la selección de pruebas admisibles hecha por el tribunal, en especial en 
ausencia de pruebas confirmadas por la presunta víctima, y la evaluación de ellas, fueron claramente arbitrarias, en violación del párrafo 1 del artículo 14 del Pacto (Comité de Derechos Humanos, 2002a, párr. 7.2).

Por otra parte, es imperioso analizar los plazos de duración de las causas judiciales. Según la Convención en su artículo 8.1 los plazos deben ser razonables, si bien la Corte Interamericana considera que estos no son de sencilla definición.

La Corte IDH ayudándose de los elementos que señala el Tribunal Europeo de Derechos Humanos (TEDH), estableció tres factores que deben tomarse en cuenta para determinar la razonabilidad del plazo en el cual se desarrolla el proceso: (i) la complejidad del asunto; (ii) la actividad procesal del interesado y (iii) la conducta de las autoridades judiciales (Corte IDH, 1997a, párr. 77; TEDH, 1991, párr. 30; TEDH, 1993, párr. 30).

La jurisprudencia interamericana dispuso que el juez debe actuar sin estar sujeto a influencia, aliciente, presión, amenaza o intromisión, directa o indirecta, sino única y exclusivamente conforme a $-y$ movido por- el derecho (Corte IDH, 2008c, párr. 56; 2012b, párr. 189).

En el caso Reverón Trujillo vs. Venezuela, la Corte precisó que los jueces, a diferencia de los demás funcionarios públicos, cuentan con garantías específicas debido a la independencia necesaria del poder judicial, lo cual la Corte entiende como "esencial para el ejercicio de la función judicial" (Corte IDH, 2009, párr. 67).

Más recientemente, podemos encontrarnos con dos sentencias dictadas en el año 2013 contra Ecuador y que encierran una serie de aspectos dignos de destacar. El primero que reseñaremos es el caso Quintana Coello y otros. Destacamos de dicho caso, la sistematización que allí se realiza de las garantías derivadas de la independencia judicial, según la misma jurisprudencia interamericana y los principios básicos de las Naciones Unidas relativos a la independencia de la judicatura. Es así como se habla de las siguientes garantías a implementarse: un adecuado proceso de nombramiento; la inamovilidad en el cargo y la garantía contra presiones externas (Corte IDH, 2013a, párrs. 145-148).

Además, en este mismo veredicto, la Corte Interamericana indica que el ejercicio autónomo de la función judicial debe garantizarlo el Estado tanto en su faceta institucional, esto es, en relación con el poder judicial como sistema (dimensión objetiva), así como en conexión con su vertiente individual, es decir, con respecto a la persona del juez específico (dimensión subjetiva). Esta dicotomía es expuesta de la siguiente forma:

El Tribunal estima pertinente precisar que la dimensión objetiva se relaciona con aspectos esenciales para el Estado de derecho, tales como el principio de separación de poderes, y el importante rol que cumple la función judicial en una democracia. Por ello, esta dimensión objetiva trasciende la figura del juez e impacta colectivamente en toda la sociedad. Así mismo, existe una relación directa entre la dimensión objetiva de la independencia judicial y el derecho de los jueces a acceder y permanecer en sus cargos en condiciones generales de igualdad, como expresión de su garantía de estabilidad (Corte IDH, 2013, párr. 154).

El fallo jurisdiccional de análisis resume los estándares deseables de acuerdo con la Convención Americana, que involucran la independencia del juez: (i) el respeto de las garantías judiciales implica respetar la independencia judicial; (ii) las dimensiones de la independencia judicial se traducen en el derecho subjetivo del juez a que su separación del cargo obedezca en exclusiva a las causales permitidas, ya sea por medio de un proceso que cumpla con las garantías judiciales o porque se ha cumplido el término o periodo de su mandato, y (iii) cuando se afecta en forma arbitraria la permanencia de los jueces en su cargo, se vulnera el derecho a la independencia judicial consagrado en el artículo 8.1 de la Convención Americana, en conjunción con el derecho de 
acceso y permanencia en condiciones generales de igualdad en un cargo público, establecido en el artículo 23.1.c de la Convención Americana.

Por su parte, en el caso Camba Campos y otros igualmente contra Ecuador, el asunto de fondo es la destitución arbitraria de ocho vocales del Tribunal Constitucional y las implicaciones que esta situación deriva para un Estado democrático. La Corte IDH resalta que en el término de catorce días se destituyó no solo al Tribunal Constitucional, sino también al Tribunal Electoral y a la Corte Suprema de Justicia, lo cual constituye un actuar intempestivo totalmente inaceptable.

Todos estos hechos afectan la independencia judicial y permiten concluir que en ese momento en Ecuador había un clima de inestabilidad institucional, que afectaba a importantes organismos del Estado. Aún dentro del anterior marco fáctico, la resolución de marras se ampara en los mismos pronunciamientos del Comité de Derechos Humanos del PIDCP, para enfatizar en que los jueces solo pueden ser removidos por faltas de disciplina graves o incompetencia y acorde con procedimientos con debidas garantías o cuando se culmine el periodo de su cargo. La destitución no puede resultar una medida arbitraria, lo cual debe analizarse a la luz del marco jurídico nacional existente y las circunstancias del caso concreto.

Ahora bien, los funcionarios judiciales removidos de su cargo solicitaron el derecho a la protección judicial en razón de la destitución inminentemente política a la que estaban siendo sometidos, siendo que el alto tribunal regional consideró que los magistrados se encontraban impedidos para hacer uso del recurso de amparo y que el recurso de inconstitucionalidad no era idóneo y efectivo para proteger los derechos vulnerados, lo cual resultó en una violación del artículo 25.1 en relación con el artículo 1.1 de la Convención Americana. En este sentido, lo importante de este razonamiento es que las personas responsables de impartir justicia, deben contar con recursos y remedios legales de plena efectividad, capaces de ser activados en situaciones como las que conoce esta sentencia. No pueden quedar excluidos o al margen del derecho, puesto que la tutela a la independencia judicial sustenta los cimientos del Estado democrático.

Precisamente en concordancia con lo expuesto, el veredicto destaca que el artículo 3 de la Carta Democrática Interamericana dispone que

[son] elementos esenciales de la democracia representativa, entre otros, el respeto a los derechos humanos y las libertades fundamentales; el acceso al poder y su ejercicio con sujeción al Estado de derecho; [...] y la separación e independencia de los poderes públicos.

La Corte concluye que la destitución de todos los miembros del Tribunal Constitucional implicó una desestabilización del orden democrático existente en ese momento en Ecuador, por cuanto se dio una ruptura en la separación e independencia de los poderes públicos al realizarse un ataque a las tres altas cortes de Ecuador en esa época. La misma instancia resalta que la separación de poderes guarda un estrecho lazo, no solo con la consolidación del régimen democrático, sino además busca preservar las libertades y derechos humanos de los ciudadanos (Corte IDH, 2013b, párr. 221).

Como puede colegirse de toda la jurisprudencia invocada, hay una preocupación constante en el sistema interamericano con respecto a los estándares de independencia judicial, como un antídoto al autoritarismo; la imposición política de los criterios judiciales y sobre todo, a la designación antojadiza de los operadores que deben dictar el derecho. Se cuestiona que la fragilidad de la institucionalidad encargada de impartir justicia, por sí misma acarrea enormes y graves consecuencias para un Estado que se precie de democrático.

\section{E. La garantía de instrucción y resolución imparcial del procedimiento a través de una correcta motivación}

Complementaria a la garantía de imparcialidad e idoneidad del juez que ya analizamos, es la consabida imparcialidad del proceso, por lo que 
vamos a reflexionar sobre algunos de sus aspectos. Volviendo a la jurisprudencia comparada, el Comité de Derechos Humanos del PIDCP distingue dentro del requisito de imparcialidad del juez, dos aspectos o dimensiones. Primero, los jueces no deben permitir que en su parecer influyan sesgos o prejuicios personales, ni tener ideas preconcebidas sobre el asunto de que conoce, ni actuar de manera alguna que promueva indebidamente los intereses de una de las partes en detrimento de la otra. Segundo, el tribunal también debe parecer imparcial a un observador razonable. Estos dos aspectos se refieren a los elementos subjetivo y objetivo de la imparcialidad, respectivamente (Comité de Derechos Humanos, 2002b, párr. 9.5; 2005, párr. 9.3).

Conviene referirse entonces a la imparcialidad del juzgador como órgano unipersonal o colegiado que dicta y declara el derecho vigente, en el marco de las más completas garantías; así como a la imparcialidad del proceso o juicio mismo, en el que se van a llevar a cabo todos los actos prejudiciales y judiciales si fuere el caso hasta llegar a la motivación de una resolución final.

Para abordar el primer tópico, el mismo Comité caracteriza aún más al elemento subjetivo, aduciendo que "la imparcialidad del juez debe presumirse en tanto no se pruebe lo contrario". A este respecto, este órgano se refiere cuando se quiso cuestionar el grado de imparcialidad, relativo a la valoración de las pruebas en el tribunal regional, en particular del hecho de que este órgano judicial aceptase la versión de los hechos del Dr W. a la vista de la prueba documental que sugería que el autor había dado su aprobación a la liquidación global. El Comité llega a la conclusión de que los antecedentes presentados no ponen de manifiesto la falta de imparcialidad subjetiva del juez en el presente caso (Comité de Derechos Humanos, 2005, párr. 9.4).

Un interesante antecedente se suscitó en el mismo Comité, en cuanto a la posible parcialidad o no de un juez que conoció en instancia una causa, que se presume podía tener interés directo, por ser igualmente funcionario docente universitario. Apuntamos al caso Laguna vs. España, en el que el Comité estima que, dado que el magistrado ponente era empleado de la universidad -una de las partes en el proceso ante el Tribunal Superior de Justicia de Murcia- en donde fungía como profesor asociado, la autora pudo razonablemente albergar dudas sobre la imparcialidad del tribunal. El Comité considera que, en estas circunstancias, las aprensiones de la autora sobre la imparcialidad del juez son objetivamente justificadas $y$, en consecuencia, no se puede considerar que haya existido un tribunal imparcial en el sentido del artículo 14, párrafo 1, del Pacto. Se concluye entonces lo siguiente:

El Comité de Derechos Humanos, actuando en virtud del párrafo 4 del artículo 5 del Protocolo Facultativo del Pacto Internacional de Derechos Civiles y Políticos, considera que los hechos que tiene ante sí ponen de manifiesto una violación del párrafo 1 del artículo 14 del Pacto.

De conformidad con las disposiciones del artículo 2, párrafo 3, inciso a) del Pacto, el Estado Parte está obligado a asegurar a la autora un recurso efectivo. El Estado Parte tiene la obligación de tomar las disposiciones necesarias para que en lo sucesivo no ocurran violaciones parecidas (Comité de Derechos Humanos, 2002b, párrs. 9-11).

El TEDH por su parte, señaló que la imparcialidad tiene aspectos tanto subjetivos como objetivos, a saber: (i) el tribunal debe carecer, de un modo subjetivo, de prejuicio personal; (ii) debe ser imparcial desde un punto de vista objetivo, es decir, debe ofrecer garantías suficientes para que no haya duda legítima al respecto. Desde el análisis objetivo, se debe determinar si, aparte del comportamiento personal de los jueces, hay hechos averiguables que podrán suscitar dudas sobre su imparcialidad. En este sentido, hasta las apariencias podrán tener cierta importancia. Lo que está en juego es la confianza que deben inspirar los tribunales a los ciudadanos en una sociedad democrática y, sobre todo, en las partes del caso (TEDH, 2002, párr. 58; 2004, párr. 27). 
En el caso Almonacid Arellano vs. Chile, el deber de instruir una determinada causa es una obligación de primer orden, llegando la Corte Interamericana a considerar que si aparecen nuevos hechos o pruebas que ayuden a establecer los responsables de violaciones a los derechos humanos, y más aún, de los responsables de crímenes de lesa humanidad, pueden ser reabiertas las investigaciones. Incluso si existe una sentencia absolutoria en calidad de cosa juzgada, dadas las exigencias de la justicia, los derechos de las víctimas y la letra y espíritu de la Convención Americana (Corte IDH, 2006, párr. 154).

\section{F. Inobservancia del principio de non bis in idem en la cosa juzgada fraudulenta}

Un aspecto que estudia la jurisprudencia interamericana en relación con la cosa juzgada fraudulenta, atañe a si el fallo dado independientemente de sus vicios, al decretarse su improcedencia, roza con la garantía procesal del principio non bis in idem -nadie puede juzgarse nuevamente por la misma falta-. En conclusión, los Estados no pueden invocar este principio garantista a su favor, indicando que existió un juicio previo y que debe respetarse los derechos y situaciones concedidas en sentencia. Sobre este último punto interesa recalcar que de acuerdo con la jurisprudencia no existe una violación al consabido principio, en el entendido que las sentencias o fallos inclusive administrativos deben respetar las reglas del debido proceso en toda su magnitud, pues de lo contrario la misma ilegalidad manifiesta de los proveídos jurisdiccionales no convalida ni constituye técnicamente cosa juzgada (Corte IDH, 2006, párr. 154).

Este es un elemento trascendental que debe tomarse en cuenta ante situaciones de cosa juzgada fraudulenta, ya que las defensas procesales de los Estados infractores en el sentido que estamos ante situaciones jurídicas firmes y con efectos jurídicos vinculantes para las partes que no podrían ser retraídos, ni mucho menos volver a juzgarse; cederían ante la invocación y visualización de lesiones tan serias a la Convención Americana al momento de impartir justicia. Estos yerros serían incompatibles con las mismas provisiones garantistas judiciales del instrumento interamericano según lo estima la Corte Interamericana.

\section{G. Los desafíos del Estado de derecho contemporáneo y su combate frontal a la fraudulencia judicial}

En este último punto nos queda por generar a título de recuento, algunos puntos que estimamos factibles para combatir desde un Estado de derecho, el flagelo de la omisión de garantías y fraudes al quehacer jurisdiccional. Son tres los retos que proponemos alcanzar:

\section{La supraconstitucionalidad de los tratados internacionales de protección de derechos humanos y su necesaria complementación con el derecho interno}

Las relaciones entre el derecho doméstico o interno y el de orden internacional han sido abordadas por el esquema clásico del derecho internacional, desde una óptica sencilla: es propio de la jurisdicción endógena de cada Estado, todo aquello que no se somete al derecho internacional, es decir, que no está regulado por ese derecho. Por el contrario, es propio del derecho internacional todo aquello regulado por una fuente del derecho internacional. Puede notarse entonces que la respuesta es tautológica y no nos arroja mayor luz en el marco de un debate conceptual, dejándose por fuera del análisis qué es lo que está entregado al derecho internacional. Así las cosas, en el marco del derecho internacional clásico, es propio de la jurisdicción internacional todo aquello que está reconocido y regulado por el derecho internacional y, dentro de tal esquema, lo regulado es solo lo que los Estados, como sujetos principales del derecho internacional, han creado y aceptado en tal carácter: lo que reconocen como parte del derecho internacional en uso de su soberanía.

Se sostiene por otra parte, que entre el derecho interno y el derecho internacional se suscita una plenitud hermética. Para Bidart Campos 
[...] como los tratados sobre derechos humanos tienen como objeto y fin propios que tales derechos se hagan efectivos en la jurisdicción interna de los Estados que son parte en dichos tratados, un sistema de derechos en un Estado democrático debe interpretarse de tal modo que logre completitud y quede cerrado a través de dos fuentes en retroalimentación: la interna de cada Estado, y la internacional (1997, p. 39).

Es decir, al ser el derecho internacional un derecho de tipo subsidiario con relación al derecho interno -que entra a desempeñar su rol en defecto o en relación de complemento-, este último derecho debe articularse a través de razones o instancias supranacionales. Como lo apunta Haba

El orden jurídico interno y el internacional conforman una estructura de sentido unitario, quedan solidariamente comprometidos a proteger los derechos humanos [...] Pues se puede afirmar que el derecho internacional público tiene hoy, además de la dimensión que se refiere a las relaciones entre los Estados mismos, una segunda dimensión, nueva: la de las obligaciones de los Estados frente a sus propios súbditos, precisamente en materia de derechos humanos (1987, p. 377).

De lo expuesto se deduce el carácter adhesivo y vinculante que ejercen las normas internacionales en el marco del sistema jurídico receptor. Resta decir entonces que el mecanismo adecuado para incorporar el DIDH al ordenamiento jurídico interno de un Estado, corresponde ineludiblemente a la

3 La Corte IDH, en su opinión consultiva OC-7/1986 del 29 de agosto, sobre "Exigibilidad del derecho de rectificación o respuesta, arts. 14.1, 1.1 y 2 de la Convención Americana sobre Derechos Humanos", establece lo siguiente: "Este artículo, ha dicho la Corte [...], escoge una regla básica del derecho internacional, según la cual todo Estado parte en un tratado tiene el deber jurídico de adoptar las medidas necesarias para cumplir con sus obligaciones conforme al tratado, sean dichas medidas legislativas o de otra índole" (párr. 30, OC-7/1986). Para el juez Gros Espiell "Este artículo [el $2^{\circ}$ ] de la Convención impone el deber a los Estados ratificación de un tratado internacional por parte del mismo. Esta incorporación por sí misma, no está exenta de tensiones desde un plano doctrinal y funcional; acarrea en los Estados dos situaciones totalmente diversas: una de ellas sería que en uso y potestades de su autodeterminación, se pueda adaptar este derecho exógeno desde un sistema jurídico sintético e integrado, mientras que la otra posición implica necesariamente tener conflictos entre el derecho internacional y el derecho doméstico o interno por estimarlos como ámbitos muy diferentes, y que consecuentemente no son capaces de relacionarse entre sí en lo absoluto.

Es de interés para el fin de esta investigación apostar por el primer caso -incorporación de los tratados al derecho interno- y para ello el artículo segundo de la Convención Americana sobre Derechos Humanos, señala la obligación de adoptar disposiciones de derecho interno que permitan el cumplimiento de las disposiciones de la Convención, en los casos en que estas no se basten a sí mismas ${ }^{3}$. Sobre este particular, Monroy Cabra manifiesta, al interpretar el tan discutido artículo segundo de la Convención Americana sobre Derechos Humanos, que

Los Estados partes se comprometen a eliminar en el ámbito de su jurisdicción todos los obstáculos que se opongan a la aplicación de la convención pero en ningún momento se adoptó la tesis dualista ni puede deducirse de su texto que los arts. 1 al 32 no se apliquen directamente [...]. Agregando: "[...] si la Convención Americana busca garantizar derechos de las personas individuales debe

partes de adoptar las medidas requeridas para hacer efectivos los derechos y libertades reconocidos por la Convención. El ser de estos derechos no está condicionado a la existencia de normas pertinentes en el derecho interno de los Estados partes. Pero estos Estados se hallan obligados a adoptar las medidas legislativas o de otro carácter, si no existieran ya, para hacer 'efectivos' tales derechos y libertades. Se trata de una obligación adicional, que se suma a la impuesta por el artículo 1 de la Convención dirigida a hacer más determinante y cierto el respeto de los derechos y libertades que la Convención reconoce". 
interpretarse de suerte tal que pueda aplicarse inmediata y directamente a los particulares" (citado por Albanese, 1991, p. 127).

Esta obligación de aceptación y recepción del DIDH a la normatividad propia, supone una estructura jurídica de interpretación diseñada para cumplir este tránsito sin ningún contratiempo. Los diferentes Estados latinoamericanos vienen incorporando en sus Cartas Políticas los rangos de distinción o supraconstitucionalidad que tienen los tratados de derechos humanos en sus jurisdicciones, teniendo como efecto jurídico que prevalezcan aún sobre la misma ley ordinaria y sobre todo, por encima de la norma constitucional.

Desde nuestra perspectiva, si no existe un verdadero monismo o sincretismo entre la ley local y la normatividad protectora de derechos humanos, difícilmente se puede llegar a ampliar el abanico de los derechos y libertades individuales y/o grupales. La jerarquía o valor del tratado internacional tiene capital relevancia al momento de ejercer la tutela de los derechos lesionados, por lo que si estamos ante un rango supraconstitucional de aquellos instrumentos que salvaguardan los derechos humanos; se suscitan dos consecuencias inmediatas de singular importancia: (i) la primera sería que le otorga margen a los justiciables para invocar la interpretación de las disposiciones del derecho internacional protector en materia de derechos humanos, con la intención de hacerlas prevalecer y autoejecutar sin mayor dilación en su entorno inmediato, $y$ (ii) si el resultado de esta invocación y solicitud de adoptar medidas congruentes con el derecho del tratado internacional en el orden interno, no acarrea los efectos deseados o simplemente no existe respuesta alguna, subiste la posibilidad de escalar el conflicto hacia los sistemas protectores de derechos humanos -universal o regionales según sea el caso-.

Por las razones expuestas consideramos que una medida para combatir la fraudulencia judicial pasa por invocar y exigir el cumplimiento de los precedentes emanados por la jurisprudencia interamericana, atinentes a los deberes de independencia judicial; imparcialidad del procedimiento; garantías plenas de debido proceso entre otras variables ya analizadas. De nada sirven los veredictos judiciales si no son factibles de otorgárseles la vinculancia debida, siendo una verdad de Perogrullo que es aplicable a los lineamientos girados por la Corte Interamericana en la materia aludida a lo largo de este trabajo.

\section{La construcción de Estado de derecho parte de la vigencia de las reglas del debido proceso como cultura de legalidad}

Para desentrañar este segundo desafío, conviene establecer inicialmente qué se entiende por Estado de derecho para los efectos de este artículo, y correlativamente, qué implica la vivencia de la cultura de la legalidad como efecto plausible del debido proceso.

Piza Rocafort (1984) precisa las características permanentes del Estado de derecho de la siguiente manera: (i) división y control mutuo de los poderes del Estado; (ii) imperio y supremacía de la Constitución y de la ley sobre la organización y actuación del Estado; (iii) control de constitucionalidad sobre la ley y legalidad sobre la función administrativa del Estado; (iv) responsabilidad del Estado y de sus funcionarios por los entuertos que cometen; (v) existencia de la democracia como forma de gobierno; $y$ (vi) existencia de garantías efectivas de respeto y operación de los derechos fundamentales de las personas. En forma más específica, los mecanismos de protección de los derechos humanos son elemento definitorio básico del Estado de derecho; $y$ este un requisito y un modo de realizar y fomentar el DIDH. Nos quedamos con esta definición al considerar que encierra los requisitos básicos que se aspiran para este tipo de Estado, aunque la teoría formalísticonormativa acaba identificándolo con primacía de la ley, principio de legalidad e igualdad formal, como postulados básicos del mismo.

Por su parte, la cultura de legalidad podría visualizarse esencialmente como ordenamiento jurídico, que es relevante únicamente al menos 
desde la técnica de producción de los mandatos jurídicos y la conexión de estos con los procedimientos que se plantean coercitivos o vinculantes en los ciudadanos como destinatarios últimos para su actuación y aplicación (división de poderes, primacía del poder legislativo sobre el poder ejecutivo y judicial, autonomía del poder judicial respecto al ejecutivo, identificación de los caracteres formales de ley, y así sucesivamente). En este sentido, José María Sauca (2010) considera que el concepto cultura de la legalidad incorpora tres elementos: el cultural -con todos sus aspectos sobre conductas desviadas, ideas del bien o componentes morales en su mayoría asumidos-; condiciones de legalidad -o Estado de derecho formal y real-y finalmente, las condiciones de legitimidad del derecho -ligado todo ello al buen gobierno y sus diferentes variables configuradoras-. Villoria y Jiménez entienden por cultura de la legalidad, "el conjunto de expectativas ciudadanas sobre el respeto a la ley y a los procedimientos legales por parte de los gobernantes, los órganos especializados en la ejecución del derecho y los ciudadanos en general" (Villoria y Jiménez, 2014, p. 97).

La cultura de la legalidad, como rasgo característico de la sociedad democrática, no es algo que una vez se alcance, resulte estable e irreversible. La experiencia enseña más bien lo contrario: en todas las democracias se registran, periódicamente, fluctuaciones (de intensidad y efectos variables) en cuanto al grado de identificación y confianza de la ciudadanía con sus instituciones. Para nuestros efectos, entendemos que la legalidad se plasma y canaliza necesariamente a través del debido proceso ${ }^{4}$, todo ello sabiendo que estamos ante reglas cuya misión es servir de garantías plenas de derechos humanos. Un Estado de derecho que se precie y cautive el respeto a lo interno y externo de su accionar, no obviaría enarbolar los estándares de derechos humanos como aquellas pautas susceptibles de observar en todos sus ámbitos. Por esta razón un combate frontal al fraude judicial, pasa inobjetablemente por el sometimiento absoluto del Estado de derecho al imperio de la legalidad, cuyo mecanismo verificable lo constituye el genuino debido proceso.
En el sistema interamericano esta garantía al debido proceso -o due process of law como dirían los anglosajones-, se recoge en el artículo octavo de la Convención Americana. Al respecto en el caso Norín Catrimán y otros vs. Chile, se ha contextualizado la citada provisión de la siguiente manera:

Para que en un proceso se respeten verdaderamente las garantías judiciales protegidas en el artículo 8 de la Convención es preciso que se observen todos los requisitos que "[sirvan] para proteger, asegurar o hacer valer la titularidad o el ejercicio de un derecho", es decir, las "condiciones que deben cumplirse para asegurar la adecuada defensa de aquellos cuyos derechos u obligaciones están bajo consideración judicial". El referido artículo 8 contempla un sistema de garantías que condicionan el ejercicio del ius puniendi del Estado buscando asegurar que el inculpado o imputado no sea sometido a decisiones arbitrarias (Corte IDH, 2014, párr. 187).

En resumen, un Estado de derecho no podría obviar las matrices procesales y materiales que confortan el acceso a un juicio justo en toda su dimensión. Es en este vínculo sinalagmático que se imponen los deberes de asegurar una correcta legalidad y respeto de la misma, consolidando una cultura ética de obediencia así como de reconstrucción de las relaciones entre lo jurídico y la ciudadanía. El debido proceso sería únicamente el reflejo sistémico de las obligaciones adecuadas y razonables que se imponen en un Estado, para

4 Para nuestros efectos vamos a entender al debido proceso como la mancomunidad de prerrogativas establecidas jurídicamente y tuteladas al más alto rango, para hacer efectiva una serie de derechos y garantías capaz de salvaguardar principios esenciales del proceso: justicia, celeridad, objetividad de la prueba, representación y derecho a defensa oportuna, entre otros. Por consiguiente, el debido proceso es un concepto evolutivo y de clausus apertus puesto que debe tener la capacidad para concretar dichos principios y otros más, según sean los niveles o etapas del asunto sometido a la instancia administrativa o judicial y las necesidades de tutela propias del ser humano. 
seguir construyendo más credibilidad entre todas las partes que interactúan en los escenarios de justiciabilidad: los jueces encargados de impartir justicia; las partes afectadas; el poder represivo; autoridades administrativas y aparataje estatal en sentido amplio, etc.

\section{La selección y formación del juez como baluarte del orden democrático}

Conviene iniciar esta sección indicando que en aras de la transparencia y eficacia requeridas para tutelar fidedignamente los derechos humanos al interior de cada país, los modelos de organización y selección de jueces no son inmunes a problemáticas de muy diversa índole que afectan su independencia y proyección propia, con relación al poder político expresado principalmente en quienes ejercen las riendas gubernamentales. Bergalli (1991), compara distintos modelos judiciales diciéndonos que modelos de organización como el anglosajón y el italiano (en consecuencia de este, también el español) tienen resueltos los problemas de selección de modo diferente. Mientras en el primero las técnicas de selección están más condicionadas por el poder político que en el segundo, en aquel la independencia se garantiza por la conciencia, difundida en la sociedad, del alto valor que se les reconoce a los jueces y no por las garantías jurídicas del tipo de las que han sido introducidas, con una eficaz aplicación en Italia. En cambio, modelos como el francés, que parece ser mucho más dependiente de los poderes políticos en sus organizaciones judiciales, exhiben mecánicas de selección diferentes aunque en la práctica ninguna de ellas garantiza la eficiencia de jueces y magistrados.

En todo caso, sea cual fuere la forma de su selección, nombramiento o incorporación al aparato judicial, el juez pronuncia el derecho en los casos sometidos a su conocimiento, por encargo de la comunidad jurídica, que se encarna en el Estado. $\mathrm{Al}$ respecto, se ha dicho entonces que

El juez deviene obligado al resolver cada caso jurídico particular, tomando en consideración las convicciones y la voluntad soberana de la comunidad jurídica en la forma en que se encuentra expresada en el derecho posi- tivo vigente, establecida, precisamente, por su poder soberano de ordenación jurídica (Espinal, 1993, p. 37).

Esta situación por sí misma, debe ponderarse con la siguiente digresión: la delegación soberana que realiza la comunidad política o en dogmática constitucional el denominado poder constituyente, a los órganos de representación y ejecución política conocidos como poder constituido, construye una relación sinalagmática entre representados y representantes. En esta dinámica, los jueces vienen a ser abanderados de la imparcialidad y garantía dispuesta en las Cartas Políticas, como un mecanismo de salvaguarda y credibilidad de la ciudadanía hacia este tipo de poder judicializador.

La Comisión Interamericana de Derechos Humanos en un informe dedicado a garantizar la independencia de los operadores de justicia, señala algunos criterios y principios que deben tomarse en cuenta en los procesos de selección y nombramiento de los jueces, en aras de ponderar la eficiencia y buen desempeño en esta función. Se resumen tales requerimientos de la siguiente manera, siendo los mismos ampliamente desarrollados por la $\mathrm{CIDH}$, a saber: (i) igualdad de condiciones y no discriminación; (ii) selección con base en el mérito y capacidades; (iii) publicidad y transparencia y (iv) duración del nombramiento (CIDH, 2013, pp. 28-37).

El orden democrático se fortalece en la medida en que exista un poder judicial fuerte como columna vertebral de rendición de cuentas a la ciudadanía. Estamos hablando de un poder constituido para declarar el derecho vigente y esta facultad requiere de las personas más preparadas para ejercer la judicatura. Los procesos de selección idóneos se constituyen a su vez, en la antesala de un cuerpo de jueces más independientes para ejecutar su función.

\section{CONSIDERACIONES FINALES}

Los derechos humanos como procesos históricos pretenden mejorar la calidad de vida de las personas, incluida la garantía de juicios justos. Hemos visto a lo largo de estas líneas que la 
normativa de la Convención Americana sobre Derechos Humanos relativa al debido proceso como antídoto de la cosa juzgada fraudulenta y expresada formalmente en la jurisprudencia de la Corte Interamericana, establece pautas que nos permiten discernir cuándo estamos ante una ilegalidad manifiesta al momento de juzgar causas, las cuales pasamos a destacar.

Primera, se han expuesto una serie de interpretaciones del artículo octavo de la Convención Americana a la luz de lo que debe entenderse por debido proceso, y cómo la denominada cosa juzgada fraudulenta se constituye en su antítesis. Basta indicar que la jurisprudencia interamericana supone la observancia del debido proceso en todas las esferas sancionatorias, por lo que su sola inobservancia constituye una violación al artículo supracitado y por ende, la cosa juzgada realizada en fraude no es congruente con la protección de los derechos humanos de las personas.

Segunda, los órganos del Estado responsables de administrar justicia tienen la obligación de prevenir la falta de garantías judiciales. Nos encontramos ante una postura activa que parte de un garantismo normativo que propicie condiciones y mecanismos tanto objetivos como factibles, al momento de decidir las causas administrativas y judiciales. Dentro de este elenco de garantismo judicial, el papel del juez es preponderante y es así como su actuación sin presiones ni influencias y su estabilidad funcional, se destacan muy claramente en la jurisprudencia del sistema interamericano, con el caso Apitz Barbera y otros vs. Venezuela, desde el año 2008 y más recientemente, con el caso Quintana Coello y otros vs. Ecuador (2013). La enseñanza que nos dejan todos estos precedentes, consiste en visualizar la imposibilidad de plenas garantías judiciales sin un compromiso del Estado de fortalecerla institucionalmente y desde la condición del propio operador de justicia.

Tercera, la necesidad de investigación y motivación de los actos administrativos y jurisdiccionales en sentido amplio ha sido un tópico abordado en el marco de la jurisprudencia y resoluciones comparadas en derechos humanos. En el ámbito del sistema interamericano, el caso Almonacid
Arellano vs. Chile, marca un importante precedente en esta materia al considerar la urgencia de instruir las causas con mucho más razón, si aparecen hechos nuevos. Así mismo, esta instrucción debe reflejarse en la integralidad de las resoluciones y demás autos interlocutorios, puesto que la observancia del debido proceso pasa necesariamente por la adecuada fundamentación de los mismos.

Cuarta, la invocación del non bis in idem no es una excusa para que los sistemas jurisdiccionales endógenos se escuden en que ya existe precedente o cosa juzgada y se imposibilite entonces, reabrir fallos pasados. El mérito de la jurisprudencia interamericana invocada, consiste en determinar que si no existió un debido proceso cristalino y en su lugar, se llega a realizar un proceso amañado, parcializado y encausado hacia la impunidad; se pueda atribuir responsabilidad al Estado por su inobservancia para adoptar medidas en contra de tales vicios procesales y se establezca su improcedencia al tenor de la misma Convención Americana.

Por último, los desafíos del Estado de derecho contemporáneo y su combate frontal a la fraudulencia judicial, podemos resumirlos de la siguiente manera:

(i) El Estado de derecho debe bastarse a sí mismo para canalizar y resolver las demandas y requerimientos de la sociedad, por lo que la normativa internacional que soporta los derechos humanos debe entronizarse con el derecho interno; (ii) en un solo intento de complementación, los ordenamientos internos y el entorno internacional deben ir consolidando una cultura de legalidad, capaz de permear la estructura jurídica hasta sus más hondas raíces y en esta tarea, es menester un cuerpo de jueces y juezas que demuestren cada día su probidad en los fallos jurisdiccionales; $y$ (iii) consideramos que solo así se puede combatir el flagelo de la cosa juzgada fraudulenta, revirtiendo su sintomatología-negación de justicia, corrupción, arbitrariedad e imparcialidad judicial-, provocando una respuesta efectiva y dispuesta a atender las nuevas demandas judiciales que tanto exige nuestro continente latinoamericano. 


\section{REFERENCIAS}

Abregú, M. (1998). La aplicación del derecho internacional de los derechos humanos por los tribunales locales: una introducción ( $2^{\mathrm{a}}$ ed.). Buenos Aires: Proyecto Regional de Justicia, Dirección Regional para América Latina y el Caribe (DRALC), Programa de las Naciones Unidas para el Desarrollo (PNUD), Editores del Puerto.

Albanese, S. (1991). Promoción y protección internacional de los derechos humanos. Buenos Aires: Ediciones La Rocca.

Bergalli, R. (1991). La quiebra de los mitos: independencia judicial y selección de jueces. Revista Nueva Sociedad, 112, marzo-abril.

Calaza, S. (2001). La cosa juzgada. Madrid: Grupo Wolters Kluwer, Temas La Ley, Temis.

Comisión Interamericana de Derechos Humanos. (2013). Garantías para la independencia de las y los operadores de justicia: hacia el fortalecimiento del acceso a la justicia y el Estado de derecho en las Américas. OEA/Ser. L/V/II. Doc. 44.

Comité de Derechos Humanos. (2002a). Comunicación CCPR/C/84/D/1089/2002, español, original: inglés, 5 de agosto de 2005.

Comité de Derechos Humanos. (2002b). Comunicación CPR/C/94/D/1122/2002, caso Laguna vs. España, original: español, 3 de noviembre de 2008.

Comité de Derechos Humanos. (2005). Comunicación CCPR/C/93/D/1437/2005, caso Jenny vs. Austria, español, original: inglés, 5 de agosto de 2008.

Corte Interamericana de Derechos Humanos. (1987a). Garantías judiciales en Estados de emergencia (arts. 27.2, 25 y 8 Convención Americana sobre Derechos Humanos). Serie A-9, opinión consultiva OC-9/1987 de 6 de octubre.

Corte Interamericana de Derechos Humanos. (1987b). El hábeas corpus bajo suspensión de garantías (arts. 27.2, 25.1 y 7.6 Convención Americana sobre Derechos Humanos). Serie A-8, opinión consultiva OC-8/1987 de 30 de enero.

Corte Interamericana de Derechos Humanos. (1988). Caso Velásquez Rodríguez vs. Honduras. Sentencia de fondo. Serie C-4 de julio de 1988.

Corte Interamericana de Derechos Humanos. (1997a). Caso Genie Lacayo vs. Nicaragua. Fondo, reparaciones y costas. Serie C-30, sentencia de 29 de enero de 1997.

Corte Interamericana de Derechos Humanos. (1997b). Caso Loayza Tamayo vs. Perú. Serie C-33, sentencia de 17 de septiembre de 1997.

Corte Interamericana de Derechos Humanos. (1999). Caso de los "Niños de la Calle" (Villagrán Morales y otros) vs. Guatemala. Fondo. Serie C-63, sentencia de 19 de noviembre de 1999.

Corte Interamericana de Derechos Humanos. (2001). Caso del Tribunal Constitucional vs. Perú. Fondo, reparaciones y costas. Serie C-71, sentencia de 31 de enero de 2001.

Corte Interamericana de Derechos Humanos. (2003a). Condición jurídica y derechos de los migrantes indocumentados. Serie A-18, opinión consultiva OC-18/2003 de 17 de septiembre.

Corte Interamericana de Derechos Humanos. (2003b). Caso Myrna Mack Chang vs. Guatemala. Fondo, reparaciones y costas. Serie C-101, sentencia de 25 de noviembre de 2003.

Corte Interamericana de Derechos Humanos. (2004). Caso Carpio Nicolle y otros vs. Guatemala. Fondo, reparaciones y costas. Serie C-117, sentencia de 22 de noviembre de 2004.

Corte Interamericana de Derechos Humanos. (2005). Caso Gutiérrez Soler vs. Colombia. Fondo, reparaciones y costas. Serie C-132, sentencia de 12 de septiembre de 2005.

Corte Interamericana de Derechos Humanos. (2006). Caso Almonacid Arellano y otros vs. 
Chile. Excepciones preliminares, fondo, reparaciones y costas. Serie C-154, sentencia de 26 de septiembre de 2006.

Corte Interamericana de Derechos Humanos. (2007). Caso de la Masacre de La Rochela vs. Colombia. Fondo, reparaciones y costas. Serie C-163, sentencia de 11 de de mayo de 2007.

Corte Interamericana de Derechos Humanos. (2008a). Caso Yvon Neptune vs. Haití. Fondo, reparaciones y costas. Serie C-180, sentencia de 6 de mayo de 2008.

Corte Interamericana de Derechos Humanos. (2008b). Caso Castañeda Gutman vs. Estados Unidos Mexicanos. Sentencia excepciones preliminares, fondo, reparaciones y costas. Serie C-184, sentencia de 6 de agosto de 2008.

Corte Interamericana de Derechos Humanos. (2008c). Caso Apitz Barbera y otros ("Corte Primera de lo Contencioso Administrativo") vs. Venezuela. Excepción preliminar, fondo, reparaciones y costas. Serie C-182, sentencia de 5 de agosto de 2008.

Corte Interamericana de Derechos Humanos. (2009). Caso Reverón Trujillo vs. Venezuela. Excepción preliminar, fondo, reparaciones y costas. Serie C-197, sentencia de 30 de junio del 2009.

Corte Interamericana de Derechos Humanos. (2012a). Caso Nadege Dorzema y otros vs. República Dominicana. Fondo, reparaciones y costas. Serie C-251, sentencia de 24 de octubre de 2012.

Corte Interamericana de Derechos Humanos. (2012b). Caso Atala Riffo y Niñas vs. Chile. Fondo, reparaciones y costas. Serie C-239, sentencia del 24 de febrero de 2012.

Corte Interamericana de Derechos Humanos. (2013a). Caso de la Corte Suprema de Justicia (Quintana Coello y otros) vs. Ecuador. Excepción preliminar, fondo, reparaciones y costas. Serie C-266, sentencia de 23 de agosto de 2013.
Corte Interamericana de Derechos Humanos. (2013b). Caso del Tribunal Constitucional (Camba Campos y otros) vs. Ecuador. Excepciones preliminares, fondo, reparaciones y costas. Serie C-268, sentencia de 28 de agosto de 2013.

Corte Interamericana de Derechos Humanos. (2014). Caso Norín Catrimán y otros (dirigentes, miembros y activistas del pueblo indígena mapuche) vs. Chile. Fondo, reparaciones y costas. Serie C-279, sentencia de 29 de mayo de 2014.

Courtis, C. (2009). El mundo prometido: escritos sobre derechos sociales y derechos humanos. México D. F.: Distribuciones Fontamara S. A.

Del Toro, M. I. (2007). El principio de subsidiariedad en el derecho internacional de los derechos humanos con especial referencia al sistema interamericano. En M. Becerra. La Corte Interamericana de Derechos Humanos a veinticinco años de su funcionamiento ( $1^{\mathrm{a}}$ ed.). México D. F.: Universidad Nacional Autónoma de México, Instituto de Investigaciones Jurídicas, Serie Doctrina Jurídica, 403.

Espinal, R. et al. (1976). El juez y la defensa de la democracia: un enfoque a partir de los derechos humanos. San José: Instituto Interamericano de Derechos Humanos.

Haba, E. (1987). Tratado de derechos humanos. Tomo I. San José: Fundación Naumann, Instituto Interamericano de Derechos Humanos.

Hitters, J. (1977). Revisión de la cosa juzgada: doctrina y jurisprudencia. La Plata: Librería Editora Platense S. R. L.

Pacheco, M. (1999). El concepto de derechos fundamentales de la persona humana. En L. Amicorum. Ensayos en honor a Héctor FixZamudio. Vol. I. San José: Unión Europea, Corte Interamericana de Derechos Humanos.

Piza, R. (1984). Notas relativas a las relaciones entre el derecho internacional de los derechos humanos y el derecho costarricense. Revista Judicial, Poder Judicial de Costa Rica, año IX, septiembre. 
Rivero, J. (2001). Constitución, derechos fundamentales y derecho privado. San José: Biblioteca Jurídica Dike, Ediciones Areté.

Sauca, J. (2010). Cultura de la legalidad. Bosquejo de exploraciones conceptuales y metodológicas. Asamblea, 22, junio.

Transparencia Internacional. (2000). Elementos para fortalecer un Sistema Nacional de Integridad. Recuperado de http://transparency.org/regional_ pages/americas/publicaciones/sourcebook_esp

Vellami, M. (2001). Naturaleza de la cosa juzgada. Buenos Aires: Ediciones Jurídicas EuropaAmérica.

Villán, C. (2002). Curso de derecho internacional de los derechos humanos. Madrid: Trotta S. A., Colección Estructuras y Procesos, Serie Derecho.

Villoria, M. \& Jiménez, F. (2014). Estado de derecho, cultura de legalidad y buena gobernanza. En
I. Wences, R. Conde y A. Bonilla (eds.). Cultura de la legalidad en Iberoamérica: desafíos y experiencias. San José: Facultad Latinoamericana de Ciencias Sociales (Flacso).

Tribunal Europeo de Derechos Humanos. (1991). Motta. Sentencia de 19 febrero de 1991. Serie A-195-A.

Tribunal Europeo de Derechos Humanos. (1993). Ruiz Mateos vs. España. Sentencia de 23 junio de 1993. Serie A-262.

Tribunal Europeo de Derechos Humanos. (2002). Caso Morris vs. Reino Unido. Sentencia de 26 de febrero del 2002.

Tribunal Europeo de Derechos Humanos. (2004). Caso de Pabla KY vs. Finlandia. Sentencia de 26 de junio del 2004. 